Migraine

\section{The danger of ignoring a migraine}

\section{N P S Bajaj, P K Morrish}

\section{Answers on $\mathrm{p} 57$.}

$\Lambda^{3}$ 31 year old man was referred with prolonged loss of vision after a typical migraine attack. His usual migraine attacks consisted of a left sided headache preceded by nausea and vomiting and a visual aura of coloured and flashing lights in both visual fields. Visual loss after his migraines could last up to one hour.

The frequency of his headaches had markedly increased eight months before presentation and these were relieved with a combination of pizotifen and naratriptan. Three weeks before presentation, he suffered a typical migraine but noticed that the visual loss after the migraine persisted as a "hole" in the vision of the left eye. Two weeks later he developed a similar scotoma in the field of the right eye with distortion of vision in that eye such that straight lines appeared wavy. He had no other relevant past medical history.

On examination, his visual acuity was restricted to perception of movement only in the left eye and 6/60 in the right eye. Fundoscopy revealed the presence of arteriolar-venous nipping, "flame shaped" and "dot and blot" retinal haemorrhages, "cotton wool" spots, and papilloedema (see fig IC and ID). Visual field assessment revealed the presence of bilateral scotomata. The remainder of his clinical examination was unremarkable, although his blood pressure was found to be markedly raised at $220 / 180 \mathrm{~mm} \mathrm{Hg}$.

Blood tests including electrolytes and full blood count were normal. Computed tomography of the brain showed symmetrical hypodense areas in the posterior temporal lobes. These hypodense areas seen on computed tomography appeared as increased signal on T2 weighted magnetic resonance imaging (MRI); further areas of increased T2 signal, not seen on the computed tomogram, were revealed in both hemispheres (fig 1A and 1B). Repeat MRI of the brain one month later was normal.

\section{QUESTIONS}

(1) What is the term used to describe the MRI brain appearance in fig 1 ?

(2) Give the underlying cause of the brain appearance in this case.

(3) Give three other causes of this condition.

(4) What is the likely cause of the fundal appearance in fig 1 ?

(5) What other investigations would you order?

Postgrad Med J 2002;78:53

\section{Authors' affiliations}

N P S Bajai, P K Morrish, Department of Neurology, Hurstwood Park Neurological Centre, Haywards Heath, Sussex, UK

Correspondence: Dr Nin Bajaj; narinderbajaj@compuserve.com

Submitted 16 November 2000

Accepted 15 February 2001
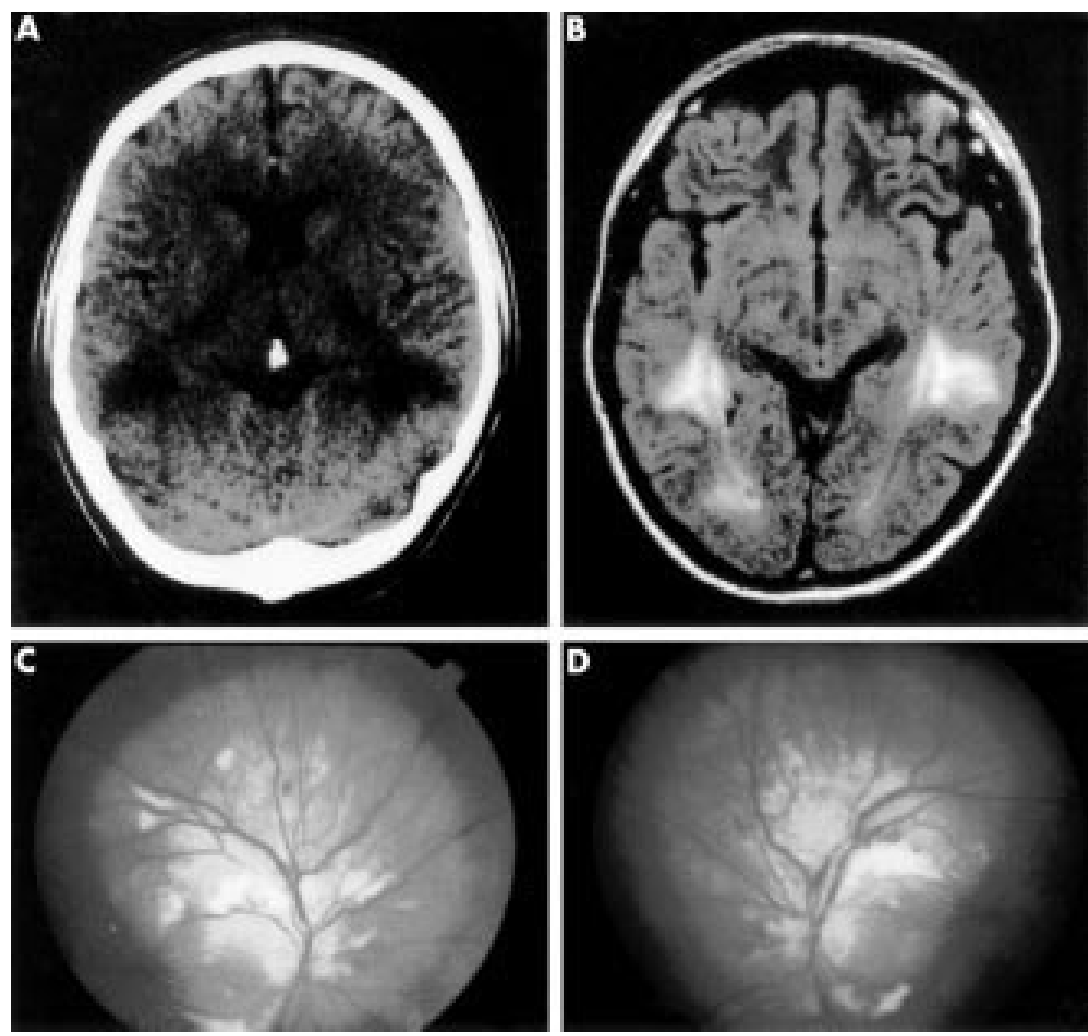

Figure 1 (A) Computed tomography of the brain and (B) FLAIR (fluid attenuated inversion recovery) sequence MRI brain shows symmetrical change in the posterior parietal and occipital lobes (seen as decreased signal on computed tomography of the brain and increased signal on FLAIR MRI). (C) and (D) illustrating fundoscopic changes including "cotton wool spots", hard exudates, arteriolar-venous nipping, "flame shaped" and "dot and blot" haemorrhages and papilloedema. 
Hyperkalaemia

\section{Hyperkalaemia in an elderly diabetic patient}

\author{
J V Butler, M Hasan
}

Answers on $\mathrm{p} 57$.

\begin{abstract}
$\mathrm{A}$ 76 year old man was referred to casualty with a non-haemolysed serum potassium of $6.6 \mathrm{mmol} / \mathrm{l}$. He was entirely asymptomatic. He had a past medical history of type II diabetes mellitus with diabetic nephropathy, hypercholesterolaemia, and cerebrovascular disease with a residual left hemiparesis from a previous stroke. He had recently increased his coffee intake and had started drinking four glasses of orange juice daily. His medications were aspirin $75 \mathrm{mg}$ daily, cerivastatin $100 \mu \mathrm{g}$ daily, gliclazide $160 \mathrm{mg}$ twice a day, and nebivolol $5 \mathrm{mg}$ daily (recently started for newly diagnosed hypertension)
\end{abstract}

On examination his blood pressure was 172/88 mm Hg and he had both left upper and lower limb weakness consistent with a previous stroke. He had some evidence of peripheral neuropathy but nothing to suggest a proximal myopathy. Examination was otherwise unremarkable. His electrocardiograph showed peaked $\mathrm{T}$ waves in most leads.

Initial investigations showed: serum sodium concentration $145 \mathrm{mmol} / \mathrm{l}$, serum potassium $6.6 \mathrm{mmol} / \mathrm{l}$, urea 11.1 $\mathrm{mmol} / \mathrm{l}$, creatinine $172 \mu \mathrm{mol} / \mathrm{l}$, glucose $4.5 \mathrm{mmol} / \mathrm{l}$, albumin $36 \mathrm{~g} / \mathrm{l}$, glycated haemoglobin $\left(\mathrm{HbA}_{\mathrm{Ic}}\right) \quad 8.3 \%$ (reference range 4.5-6.5). A 24 hour urinary creati- nine clearance was $56 \mathrm{ml} / \mathrm{min}$ while 24 hour urinary protein was raised at 1.67 g/24 hours. Serum aldosterone was 100 (100-450) pmol/l and serum renin was $<0.2(1.1-2.7) \mathrm{pmol} / \mathrm{ml} /$ hour. One year previously his biochemistry showed: serum sodium $143 \mathrm{mmol} / \mathrm{l}$, potassium $5.4 \mathrm{mmol} / \mathrm{l}$, urea $9.9 \mathrm{mmol} / \mathrm{l}$, creatinine $143 \mu \mathrm{mol} / \mathrm{l}$, and glucose $5.9 \mathrm{mmol} / \mathrm{l}$.

\section{QUESTIONS}

(1) What are the factors causing his hyperkalaemia?

(2) Why are elderly patients prone to developing hyperkalaemia?

(3) How would you manage this patient?

Postgrad Med J 2002;78:54

\section{Authors' affiliations}

J V Butler, M Hasan, Department of Geriatric Medicine, Caerphilly District Miners Hospital, Gwent Healthcare NHS Trust and University College of Medicine, Cardiff, Wales

Correspondence to: Dr M Hasan, Caerphilly District Miners' Hospital, St Martin's Road, Caerphilly CF83 2WW, UK; hasanm@cf.ac.uk

Submitted 18 December 2000

Accepted 23 January 2001

\section{QUESTIONS}

Occlusive vasculitis

(1) What is the initial diagnosis?

(2) What does the unenhanced computed tomogram of the brain show?

(3) What probable complication of the initial diagnosis has occurred?

(4) What further investigation will you do to confirm the complication?

(5) What is the treatment of this complication?

Postgrad Med J 2002;78:54

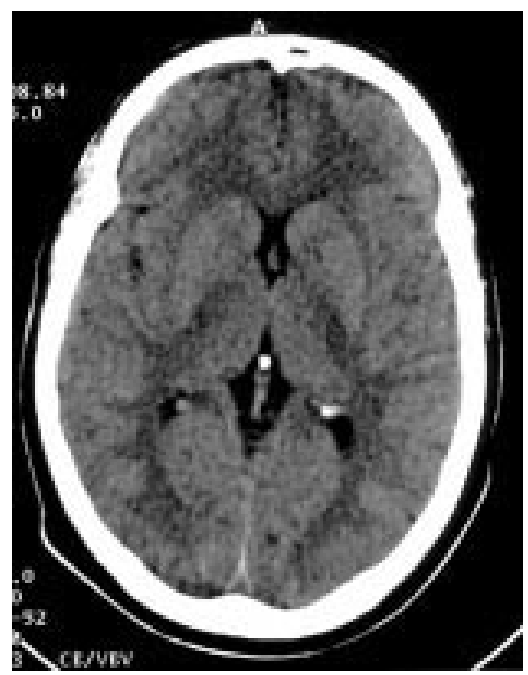

Figure 1 Unenhanced computed tomogram of brain.

\section{Authors' affiliations}

M A Mahyoub Abbas, R Cotta, W Rashid,

Correspondence to: Dr M A Mahyoub Abbas, Department of Radiology, Royal Victoria Infirmary, Queen Victoria Road, Newcastle upon Tyne NEl 4LP, UK ;

maf.abbas@doctors.org.uk

Submitted 1 June 1999

Accepted 2 October 2000 Conquest Hospital, Hastings, Sussex, UK 
Pulmonary disease

\section{Malaise, weight loss, and respiratory symptoms}

\section{H A Hadi, A G Arnold}

Answers on $p 58$.
A 58 year schoolteacher was admitted with a two month history of malaise, weight loss, worsening dyspnoea, and dry cough. There was no improvement after a course of antibiotics. There were no symptoms of arthralgia, wheezing, or fever. The patient, a non-smoker, had no history of exposure to animals and no relevant occupational or family history. She was generally in good health, apart from recurrent urinary tract infections.

On clinical examination she was apyrexial, with a respiratory rate of 20 breaths/min and an oxygen saturation of $90 \%$ on air. Examination of the cardiovascular, abdominal, and musculoskeletal systems was unremarkable. Chest examination showed decreased expansion and bilateral basal inspiratory crackles on auscultation.
Serum electrolytes, renal function, and urinalysis results were normal Blood culture was negative. A blood count showed a haemoglobin concentration of $140 \mathrm{~g} / \mathrm{l}$ and a white cell count of $12.5 \times 10^{9} / \mathrm{l}$ (neutrophils $84 \%$, eosinophils $0.6 \%$ ). The erythrocyte sedimentation rate (ESR) was $51 \mathrm{~mm} /$ hour. The electrocardiogram was uremarkable, and arterial blood gas measurements while breathing room air were normal. Lung function tests showed a forced expiratory volume in one second of 1.52 litres $(55 \%$ of predicted) and vital capacity of 1.76 litre (54\% of predicted). Flow volume loops were abnormal (fig l). Imaging investigation included a chest radiograph (fig 2) and a high resolution computed tomography (HRCT) scan of the thorax (fig 3).

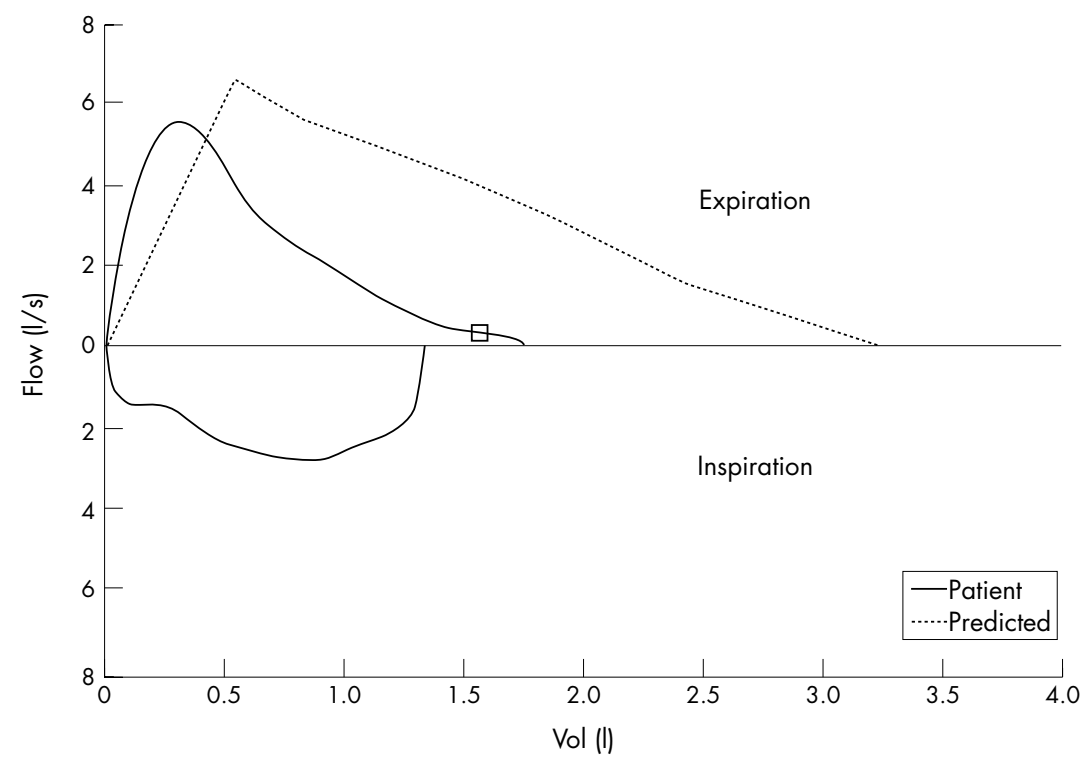

Figure 1 Flow volume loop.

\section{QUESTIONS}

(1) What abnormalities are shown in the flow volume loops?

(2) What abnormalities are shown in the chest radiograph and computed tomogram?

(3) What is the differential diagnosis?

Postgrad Med J 2002;78:55

\section{Authors' affiliations}

H A Hadi, A G Arnold, Department of Chest Medicine, Castle Hill Hospital, East Yorkshire HUl6 5JQ, UK

\section{Correspondence to: Dr Arnold}

Submitted 4 December 2000

Accepted 15 February 2001

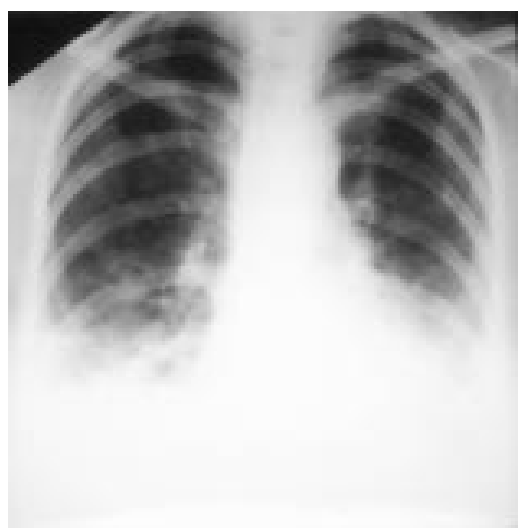

Figure 2 Chest radiograph.

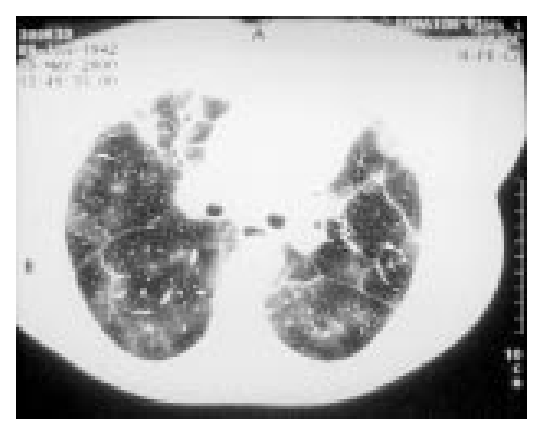

Figure 3 HRCT scan of the thorax. 


\section{QUESTIONS}

\section{Jaundice in primary school pupils}

\section{Stephenson, P Monk, J Gray, H Thuraisingam}

Answers on p 59.

A previously well 10 year old boy was admitted from school with increasing epigastric pain and vomiting. He had a six day history of feeling generally unwell and feverish with loose motions. On examination he was well, pyrexial at $37.6^{\circ} \mathrm{C}$ and mildly icteric with epigastric tenderness. There was no organomegaly. Investigations included normal full blood count, differential white count, urea, electrolytes, and chest radiography. Liver function was mildly deranged with alanine aminotransferase (ALT) $250 \mathrm{U} / \mathrm{l}$, alkaline phosphatase (ALP) $280 \mathrm{U} / \mathrm{l}$, and bilirubin $67 \mu \mathrm{mol} / \mathrm{l}$.
Paul-Bunnell test and hepatitis B surface antigen were negative. A diagnostic test was performed. He improved after 48 hours and was discharged home well.

Ten days later, a teacher from the same school presented to her general practitioner with nausea, vomiting, abdominal pain, and jaundice. On examination she was deeply icteric with no stigmata of chronic liver disease. Investigations revealed a normal full blood count with deranged liver function of ALT 1900 U/l, ALP $180 \mathrm{U} / \mathrm{l}$, and bilirubin $142 \mu \mathrm{mol} / \mathrm{l}$. Hepatitis B surface antigen and hepatitis $\mathrm{C}$ antibody were negative. A diagnostic test was performed.
(1) What is the likely and differential diagnosis?

(2) What was the diagnostic test performed?

(3) What are the risk factors for contracting this condition?

(4) What is the management approach to the control of this condition?

Postgrad Med J 2002;78:56

\section{Authors' affiliation}

I Stephenson, Department of Infectious

Diseases and Tropical Medicine, Leicester Royal Infirmary, Leicester LE 1 5WW, UK

P Monk, J Gray, H Thuraisingam,

Department of Communicable Disease Control and Public Health Medicine, Leicestershire Health, Leicester, UK

Correspondence to: Dr Stephenson; istephen@globalnet.co.uk

Submitted 8 December 2000

Accepted 25 January 2001 